\title{
Assessment of Heart Rate Variability in Early Post-menopausal Women
}

\author{
Soundirarajan Subhashri', Pravati Pal ${ }^{1, *}$, Dasari Papa ${ }^{2}$, Nivedita Nanda ${ }^{3}$, Gopal Krushna Pal', \\ Rajaa Muthu Packirisamy ${ }^{3}$
}

\section{Soundirarajan Subhashri ${ }^{1}$, Pravati Pal ${ }^{1, *}$, Dasari Papa ${ }^{2}$, Nivedita $\mathrm{Nanda}^{3}$, Gopal Krushna Pal', Rajaa Muthu Packirisamy ${ }^{3}$}

\author{
'Department of Physiology, JIPMER, \\ Puducherry, INDIA. \\ ${ }^{2}$ Department of Obstetrics and \\ Gynecology, JIPMER, Puducherry, INDIA. \\ ${ }^{3}$ Department of Biochemistry, JIPMER, \\ Puducherry, INDIA.
}

\section{Correspondence}

\section{Dr. Pravati Pal}

Professor and Head, Department of Physiology, JIPMER, Puducherry- 605 006, INDIA.

Phone: +919360682406

Email: drpravatipal@gmail.com

\section{History}

- Submission Date: 12-12-2018.

- Review completed: 05-01-2019;

- Accepted Date: 21-01-2019.

DOI : 10.5530/ijcep.2019.6.1.4

\section{Copyright}

(C) 2019 Phcog.Net. This is an openaccess article distributed under the terms of the Creative Commons Attribution 4.0 International license.

\begin{abstract}
Background and Aim: Menopause marks to a point in time that follows after the permanent stoppage of menstruation. Menopausal transition includes various autonomic dysfunctions. Age is known to affect autonomic function. Therefore, in the present study the effect of menopause on autonomic function has been assessed by comparing the heart rate variability parameters between early postmenopausal and late premenopausal women. Methods: Premenopausal and postmenopausal women of age group between 40-55 years were recruited and short term HRV was measured using BIOPAC and analysed with kubios software. Results: In postmenopausal women, HFnu was significantly reduced, LFnu, LF: $\mathrm{HF}$ ratio were significantly increased and among the time domain parameters, RMSSD was significantly reduced in postmenopausal women. Conclusion: Sympathovagal imbalance in the form of increased sympathetic and decreased parasympathetic activity was found in early postmenopausal women. There was considerable decrease in vagal indices in postmenopausal women which is known to increase cardiovascular risks.
\end{abstract}

Key words: Heart rate variability, Early postmenopausal women, Premenopausal women, Sympathovagal imbalance, LF - HF ratio.

\section{INTRODUCTION}

Menopause is a Greek word meaning, 'meno'month, 'pause'-ceases. ${ }^{[1]}$ It is a gradual transition from the reproductive to the post-reproductive stage of womens' life. ${ }^{[2]}$ Menopause marks to a point in time that follows after the permanent stoppage of menstruation. ${ }^{[3]}$ According to the third consensus meeting of Indian Menopause Society (2008), India has about 43 million women in postmenopausal age group. Menopausal transition includes autonomic dysfunctions like somatic symptoms, vasomotor symptoms, sexual dysfunctions, urological symptoms, psychological and mental disturbances such as mood changes, insomnia, depression, irritability, forgetfulness and lack of concentration that decreases the quality of life. ${ }^{[4]}$ These climacteric vasomotor symptoms are due to alteration of autonomic hemodynamic regulation like various cardiovascular reflexes and dysregulation of cutaneous blood flow. ${ }^{[5]}$ Power spectral analysis of Heart Rate Variability (HRV $)^{[6]}$ has been documented as sensitive measures of cardiovascular autonomic regulation.

Previous study demonstrated reduced heart rate variability in postmenopausal women compared to young women. ${ }^{[7]}$ There was also reports of reduced parasympathetic and increased sympathetic activities in postmenopausal women when compared to premenopausal women. ${ }^{[8,9]}$ As hypertension, ${ }^{[10]}$ diabetes mellitus $^{[11]}$ and high Body Mass Index (BMI) ${ }^{[12]}$ have

Cite this article: Subhashri S, Pal P, Papa D, Nanda N, Pal GK, Packirisamy RM. Assessment of Heart Rate Variability in Early Post-menopausal Women. Int J Clin Exp Physiol. 2019;6(1):11-4. 


\section{Inclusion Criteria}

- Premenopausal Group: Normal healthy women of age group 40-55 years with regular menstrual cycles.

- Postmenopausal Group: Normal healthy women of age group 40-55 years whose menstruation stopped at least one year before.

\section{Exclusion Criteria}

Women having hypertension, diabetes, heart disease, any chronic disease or associated factors that may affect the autonomic reflexes, neurological or psychiatric diseases, chronic alcoholics, women receiving hormone replacement therapy and any medication that have been reported to affect autonomic function (like for instance autonomic blockers), perimenopausal women (having irregular menstrual cycles) and women who underwent surgical menopause.

\section{Recording of Anthropometric and Basal Cardiovascular Parameters}

The age, height $(\mathrm{cm})$ was measured by stadiometer (BHH6, Easy Care, Mumbai, India), body weight was measured with minimal clothing by digital weighing machine (MS 4900, Charder Electronics Co. Ltd, Taichung, Taiwan) to its nearest value, BMI was calculated by 'Quetelet's index' $\left(\mathrm{BMI}=\right.$ weight $(\mathrm{Kg}) /$ height $\left.^{2}(\mathrm{~m})\right)$.

After 10 min of rest in supine position, basal heart rate, Systolic Blood Pressure (SBP) and Diastolic Blood Pressure (DBP) were measured by oscillometric method using an automatic (digital) blood pressure monitor (Omron automatic blood pressure monitor HEM-8712). Pulse Pressure (PP) was calculated as the difference between SBP and DBP (SBP-DBP). Mean Arterial Pressure (MAP) was calculated as DBP + 1/3 of PP. ${ }^{[14]}$

\section{Assessment of Heart Rate Variability}

After 10 min of rest in supine position, lead II ECG was recorded for 5-10 min as per the Task force guidelines ${ }^{[15]}$ on HRV. For this purpose, ECG electrodes were connected and lead II ECG was acquired during supine rest using a BIOPAC MP 150 data acquisition system (BIOPAC Inc., Goleta, California, United States). The data were transferred to a personal computer with acqknowledge software version 4.2. RR tachogram was extracted. HRV analysis was done using the HRV analysis software version 2.0 (Bio-signal Analysis Group, Kuopio, Finland).

\section{Measurement of Hormonal Assay}

Hormonal assay of Estrogen (CALBIOTECH-USA), Progesterone (CALBIOTECH-USA) and Follicular Stimulating Hormone (FSH) (CALBIOTECH-USA) were measured by commercially available ELISA kits.

\section{Statistical Analysis}

Statistical analysis was performed by SPSS version 19 (SPSS; SPSS Inc., Chicogo, IL). Kolmogorov-Smirnov test was used to test the normality of the data. Continuous variables were expressed as mean $\pm \mathrm{SD}$. Between the groups, normally distributed parameters were tested by unpaired student's t test and non-normally distributed parameters were tested by Mann-Whitney $U$ test. $P$-value less than 0.05 was considered statistically significant.

\section{RESULTS}

Hormonal profile shows a significant increase in follicular stimulating hormone level $(P<0.00)$ and a significant decrease in Estrogen $(P<0.00)$ and progesterone $(P=0.03)$ (Table 1$)$ in postmenopausal group compared to premenopausal group.
Anthropometric parameters such as height, body weight and BMI did not show statistically significant difference between premenopausal and postmenopausal women. Age showed a significant increase between the groups $(P<0.00)$. (Table 2$)$ There was a statistically significant difference in SBP $(P<0.00), \mathrm{DBP}(P=0.02)$, pulse pressure $(P<0.00)$ and mean arterial pressure $(P<0.00)$ in the postmenopausal group compared to premenopausal group.

On analysis of frequency domain parameters of heart rate variability, HFnu was significantly reduced $(P<0.00)$ and LFnu $(P<0.00)$, LF: HF ratio $(P<0.00)$ were significantly increased (Table 3$)$ in postmenopausal group when compared to premenopausal group. On analysis of time domain parameters, RMSSD was significantly less $(P<0.00)$ in postmenopausal group compared to premenopausal group, whereas SDNN $(P=0.27)$, NN50 $(P=0.42)$ and pNN50 $(P=0.30)$ showed no statistical difference between the groups (Table 4$)$.

\section{DISCUSSION}

We carried out short term Heart rate variability in women of 40-55 years and compared the parameters between pre- and post-menopausal women, who were non-diabetic, non-hypertensives and BMI matched. To confirm with their menopausal status we have measured hormonal level of Follicular Stimulating Hormone (FSH), Estrogen and progesterone in both the groups. Previous studies show that FSH level higher than $21 \mathrm{mIU} / \mathrm{mL}$ can be used as an independent criterion for classifying the natural menopausal status of a women with high accuracy. ${ }^{[16]}$ So these criteria of high FSH level along with amenorrhea for at least 12 months confirms the postmenopausal status in the postmenopausal group. ${ }^{[16]}$

Table 1: Comparison of hormonal level in premenopausal and postmenopausal group.

\begin{tabular}{cccc|} 
Parameters & $\begin{array}{c}\text { Premenopausal } \\
\text { Group }(\boldsymbol{n}=55)\end{array}$ & $\begin{array}{c}\text { Postmenopausal } \\
\text { Group }(\boldsymbol{n}=50)\end{array}$ & $\begin{array}{c}\boldsymbol{P} \\
\text { value }\end{array}$ \\
\hline FSH $(\mathrm{mIU} / \mathrm{ml}){ }^{\#}$ & $6.65 \pm 5.27$ & $37.61 \pm 13.68$ & $0.00^{*}$ \\
Progesterone $(\mathrm{ng} / \mathrm{ml})$ & $13.03 \pm 5.76$ & $10.96 \pm 3.81$ & $0.03^{*}$ \\
Estrogen $(\mathrm{pg} / \mathrm{mL})$ & $282.01 \pm 139.84$ & $83.58 \pm 34.09$ & $0.00^{*}$
\end{tabular}

The values are expressed as Mean $\pm \mathrm{SD}$; Statistical analysis was done by student unpaired t-test. \# by Mann-Whitney $\mathrm{U}$ test The $P$ value $<0.05$ was considered statistically significant. FSH: Follicular Stimulating Hormone.

Table 2: Comparison of age, anthropometric indices and basal cardiovascular parameters between premenopausal and postmenopausal group.

$\begin{array}{cccc}\text { Parameters } & \begin{array}{c}\text { Premenopausal } \\ \text { group }(\boldsymbol{n}=55)\end{array} & \begin{array}{c}\text { Postmenopausal } \\ \text { Group }(\boldsymbol{n}=\mathbf{5 0})\end{array} & \text { P value } \\ \text { Age }(\text { years })^{*} & 42.47 \pm 2.76 & 50.56 \pm 3.21 & 0.00^{*} \\ \text { Height }(\mathrm{cm}) & 151.70 \pm 5.40 & 151.00 \pm 5.32 & 0.50 \\ \text { Weight }(\mathrm{Kg}) & 62.00 \pm 10.32 & 61.26 \pm 12.04 & 0.73 \\ \text { BMI }\left(\mathrm{kg} / \mathrm{m}^{2}\right) & 26.92 \pm 4.17 & 26.74 \pm 4.56 & 0.82 \\ \text { BHR }(\text { per min) } & 71.67 \pm 8.47 & 75.24 \pm 8.51 & 0.03^{*} \\ \text { SBP }(\mathrm{mmHg}) & 115.14 \pm 9.43 & 124.17 \pm 11.97 & 0.00^{*} \\ \text { DBP }(\mathrm{mmHg}) & 65.67 \pm 8.29 & 69.45 \pm 9.26 & 0.02^{*} \\ \text { PP }(\mathrm{mmHg}) & 49.46 \pm 7.32 & 54.71 \pm 8.20 & 0.00^{*} \\ \text { MAP }(\mathrm{mmHg}) & 82.16 \pm 7.97 & 87.69 \pm 9.49 & 0.00^{*}\end{array}$

The values are expressed as Mean \pm SD; Statistical analysis was done by Student's unpaired $t$-test. \# by Mann-Whitney $U$ test. The $P$ value $<0.05$ was considered statistically significant. 
Table 3: Comparison of frequency domain indices between premenopausal and postmenopausal group.

\begin{tabular}{cccc|} 
Parameters & $\begin{array}{c}\text { Premenopausal group } \\
(\boldsymbol{n}=55)\end{array}$ & $\begin{array}{c}\text { Postmenopausal } \\
\text { Group }(\boldsymbol{n}=50)\end{array}$ & $\begin{array}{c}\boldsymbol{P} \\
\text { value }\end{array}$ \\
$\begin{array}{c}\text { Total power } \\
\left(\mathrm{ms}^{2}\right)\end{array}$ & $1418.25 \pm 612.31$ & $1222.34 \pm 574.85$ & 0.09 \\
LFnu $\left(\mathrm{ms}^{2}\right)$ & $46.20 \pm 19.88$ & $54.29 \pm 8.09$ & $0.00^{*}$ \\
$\mathrm{HFnu}\left(\mathrm{ms}^{2}\right)$ & $53.79 \pm 19.88$ & $45.70 \pm 8.09$ & $0.00^{*}$ \\
LF: HF & $0.95 \pm 0.64$ & $1.25 \pm 0.41$ & $0.00^{*}$ \\
$\left(\mathrm{~ms}^{2}\right)^{*}$ & & & \\
\hline
\end{tabular}

The values are expressed as Mean \pm SD; Statistical analysis was done by Student's unpaired $t$-test. \# by Mann-Whitney $\mathrm{U}$ test. LFnu: normalised low frequency; HFnu: normalised high frequency; LF: HF: ratio of the low frequency to the high frequency.

Table 4: Comparison of time domain indices between premenopausal and postmenopausal group.

\begin{tabular}{cccc} 
Parameters & $\begin{array}{c}\text { Premenopausal group } \\
(\boldsymbol{n}=\mathbf{5 5})\end{array}$ & $\begin{array}{c}\text { Postmenopausal } \\
\text { Group }(\boldsymbol{n}=\mathbf{5 0})\end{array}$ & $\begin{array}{c}\boldsymbol{P} \\
\text { value }\end{array}$ \\
\hline SDNN (ms) & $41.09 \pm 20.27$ & $37.17 \pm 15.65$ & 0.27 \\
RMSSD (ms) ${ }^{*}$ & $38.22 \pm 21.61$ & $29.33 \pm 20.40$ & $0.00^{*}$ \\
NN50 (count) & $35.92 \pm 27.23$ & $27.30 \pm 17.46$ & 0.42 \\
pNN50 (\%) & $10.35 \pm 5.19$ & $9.37 \pm 4.57$ & 0.30
\end{tabular}

The values are expressed as Mean \pm SD; Statistical analysis was done by Student's unpaired $t$-test. \# by Mann-Whitney U test. SDNN: standard deviation of the averages of the NN intervals in all 5 min segments; RMSSD: Square root of the mean squared differences of successive normal to normal intervals; NN50: number of interval differences of successive NN intervals greater than 50ms; pNN50: Proportion derived by dividing NN50 by the total number of NN intervals.

Though the recruitment age range was narrow to minimize the effect of age on autonomic function, age difference between the two groups was statistically significant. However, the mean age difference of 8 years might not have influenced autonomic functions, as it has been reported that autonomic function does not vary over the age range of $40-60$ years. ${ }^{[13]}$

Resting heart rate is mainly determined by the vagal action over the SA node. ${ }^{[17]}$ In the present study, the resting heart rate was significantly accentuated in postmenopausal women compared to the premenopausal women, indicating decreased vagal tone in postmenopausal women. Our results are consistent with the study by Brock bank et al. ${ }^{[18]}$ and Danuta $\mathrm{C}$ et al. ${ }^{[19]}$ The decrease in vagal tone is further confirmed by reduction in HRV parameters in postmenopausal women in the form of decreased HFnu and RMSSD, as HFnu and RMSSD are parasympathetic markers and specially RMSSD is one of the most sensitive parameters of parasympathetic tone in short term recording of heat rate variability. ${ }^{[7]}$ In a study by Neufeld et al. ${ }^{[20]}$ RMSSD was significantly higher in postmenopausal women, which could be due to difference in BMI or regular physical activity in their subjects (which is not mentioned), as physically active postmenopausal women are reported to have higher vagal tone compared to sedentary and less active postmenopausal women. ${ }^{[21]}$ Our result is similar to reports of Neves VF and Ribeiro TF, ${ }^{[7,22]}$ where significant decrease in RMSSD was observed in postmenopausal women. Thus, there was vagal withdrawal after menopause.

The resting cardiovascular parameters such as SBP, DBP, PP and MAP were significantly increased in postmenopausal women suggesting increased sympathetic tone in them as these parameters are indicators of sympathetic activity. Another study also showed similar results in blood pressure changes. ${ }^{[9]}$ However, in this study, the premenopausal women were much younger compared to the postmenopausal group (33.83yrs Vs 51.03yrs) and there was significant difference in BMI (21.28 Vs 24.73), which could have contributed to the difference in BP.

In the present study, LF: HF ratio was significantly raised in the postmenopausal group which could be due to increased sympathetic and decreased parasympathetic activity. Further increase in sympathetic activity in the postmenopausal group was demonstrated by more LFnu, which reflects absolute power of sympathetic drive over heart. Decreased parasympathetic activity was also confirmed by decreased HFnu in the same group, as HFnu represents the absolute power of parasympathetic activity over the heart. ${ }^{[23]}$ Total power in heart rate variability, measured as the variance of RR interval through the entire recording represents the vagal influence over heart. ${ }^{[23]}$ In our study there was a decrease in total power among the postmenopausal women compared to premenopausal controls but it was not found to be statistically significant which could be due to rise in LF power in postmenopausal women. These findings were in conformity with the earlier study which showed similar results in postmenopausal group without estrogen therapy when compared to premenopausal group. ${ }^{[22]}$

So, our study demonstrated a shift of autonomic functions in postmenopausal women, who tend to move towards sympathetic over activity and vagal withdrawal compared to premenopausal women. Further in this study, there was considerable decrease in vagal indices in postmenopausal women which is known to increase the risk of cardiovascular disease.

The novelty of the study is that we have compared the effect of menopause on heart rate variability within a narrow age range of 40-55 years, so that the effect of age per se on heart rate variability is minimized.

\section{Limitations of the Study}

Though $24 \mathrm{hr}$ heart rate variability measurement gives a detailed HRV values, we have performed 5 min HRV recording. Our sample size is not large and we have not assessed plasma cortisol level for sympathetic function.

\section{CONCLUSION}

Sympathovagal imbalance in the form of increased sympathetic and decreased parasympathetic activity was found in early postmenopausal women. Nevertheless, there was considerable decrease in vagal indices in postmenopausal women which is known to increase cardiovascular risks.

\section{FINANCIAL SUPPORT AND SPONSORSHIP}

This study was funded by intramural grant of JIPMER, Puducherry, for the first author as a part of postgraduate research funding.

\section{ACKNOWLEDGEMENT}

I sincerely acknowledge all my study participants.

\section{CONFLICT OF INTEREST}

The authors declare no conflict of interest.

\section{ABBREVIATIONS}

HRV: Heart Rate Variability; BMI: Body Mass Index; BHR: Basal Heart Rate; SBP: Systolic Blood Pressure; DBP: Diastolic Blood Pressure; PP: Pulse Pressure; MAP: Mean Arterial Pressure; LFnu: Normalised Low Frequency; HFnu: Normalised High Frequency; LF, HF: Ratio of the low frequency to the high frequency; SDNN: Standard deviation of the averages of the NN intervals in all 5 min segments; RMSSD: Square root of the mean squared differences of successive normal to normal intervals; 
NN50: Number of interval differences of successive NN intervals greater than 50ms; pNN50: Proportion derived by dividing NN50 by the total number of NN intervals; FSH: Follicular Stimulating Hormone.

\section{REFERENCES}

1. Cyriac SL, Viswanath L, Philip AT. Menopausal Problems among Postmenopausal Women. J South Asian Fed Menopause Soc. 2016;4(2):88-92.

2. Dutta R, Dcruze L. A Population Based Study on the Menopausal Symptoms in a Rural Area of Tamil Nadu, India. J Clin Diagn Res. 2012;6(4):597-01.

3. Sherman S. Defining the menopausal transition. Am J Med. 2005;118(12):3-7.

4. Unni J. Third consensus meeting of Indian Menopause Society: A summary. J Life Health. 2010;1(1):43-7.

5. Bhat AN, Sadhoo AK, Yograj S, Kaur G. Autonomic functions in postmenopausal women. JK Science. 2005;7(3):135-9.

6. Malliani A. Heart rate variability: from bench to bedside. Eur J Intern Med. 2005; 16(1):12-20.

7. Ribeiro TF, Azevedo GD, Crescêncio JC, Marães VRFS, Papa V, Catai AM, et al. Heart rate variability under resting conditions in postmenopausal and young women. Braz J Med Biol Res. 2001;34(7):871-7.

8. Joshi P. Shinde P. A comparative study of autonomic function tests in normotensive premenopausal and postmenopausal women. Natl J Physiol Pharm Pharmacol. 2015;5(5):386-90.

9. Gautam S, Shankar N, Tandon OP, Goel N. Comparison of cardiac autonomic functions among postmenopausal women with and without hormone replacement therapy and premenopausal women. Indian J Physiol Pharmacol. 2011;55(4):297-03

10. Singh JP, Larson MG, Tsuji H, Evans JC, O'Donnell CJ, Levy D. Reduced Heart Rate Variability and New-Onset Hypertension: Insights into Pathogenesis of Hypertension: The Framingham Heart Study. Hypertension. 1998;32(2):293-7.

11. Kudat H, Akkaya V, Sozen A, Salman S, Demirel S, Ozcan M, et al. Heart Rate Variability in Diabetes Patients. J Int Med Res. 2006;34(3):291-6.

12. Karason K, Mølgaard H, Wikstrand J, Sjöström L. Heart rate variability in obesity and the effect of weight loss. Am J Cardiol. 1999;83(8):1242-7.

13. Umetani K, Singer DH, McCraty R, Atkinson M. Twenty-Four Hour Time Domain Heart Rate Variability and Heart Rate: Relations to Age and Gender Over Nine Decades. J Am Coll Cardiol. 1998;31(3):593-601.

14. Pal GK, Pal P. Measurement of Blood Pressure. In:Textbook of Practical Physiology. Chennai: Universities Press. 2016;201-11.

15. Heart Rate Variability. Standards of measurement, physiological interpretation and clinical use. Task Force of the European Society of Cardiology and the North American Society of Pacing and Electrophysiology. Eur Heart J. 1996;17:354-81.

16. Polesel DN, Nozoe KT, Sanchez ZM, Prado MCO, Bittencourt LR, Tufik S, et al. The Follicle-Stimulating Hormone as Best Classifier for Diagnosis of Natural Menopause. J Gynecol Surg. 2017;33(6):236-42.

17. Jensen MT, Suadicani $P$, Hein HO, Gyntelberg F. Elevated resting heart rate, physical fitness and all-cause mortality: a 16-year follow-up in the Copenhagen Male Study. Heart. 2013;99(12):882-7.

18. Brockbank CL, Chatterjee F, Bruce SA, Woledge RC. Heart Rate and its Variability Change after the Menopause. Exp Physiol. 2000;85(3):327-30.

19. Czarnecka D, Posnik-Urbanska A, Kawecka-Jaszcz K, Kolasinska-Kloch W, Wojciechowska W, Fedak D. Indices of autonomic nervous system activity in women with mild hypertension in the perimenopausal period. Kardiol Pol. 2009;67(3):243-51.

20. Neufeld IW, Kiselev AR, Karavaev AS, Prokhorov MD, Gridnev VI, Ponomarenko VI, et al. Autonomic control of cardiovascular system in pre- and postmenopausal women: a cross-sectional study. J Turk Ger Gynecol Assoc. 2015;16(1):11-20.

21. Davy KP, Miniclier NL, Taylor JA, Stevenson ET, Seals DR. Elevated heart rate variability in physically active postmenopausal women: a cardioprotective effect?. Am J Physiol Heart Circ Physiol. 1996;271(2):455-60.

22. Neves VFC. Autonomic modulation of heart rate of young and postmenopausal women undergoing estrogen therapy. Braz J Med Biol Res. 2007;40(4):491-9.

23. Pal GK. Yoga and heart rate variability. Int J Clin Exp Physiol. 2015;2(1):2-9.

Cite this article: Subhashri S, Pal P, Papa D, Nanda N, Pal GK, Packirisamy RM. Assessment of Heart Rate Variability in Early Post-menopausal Women. Int J Clin Exp Physiol. 2019;6(1):11-4. 